Review

\title{
On the Relationships between LncRNAs and Other Orchestrating Regulators: Role of the Circadian System
}

\author{
Rüdiger Hardeland \\ Johann Friedrich Blumenbach Institute of Zoology and Anthropology, University of Göttingen, Bürgerstr. 50, \\ D-37073 Göttingen, Germany; rhardel@gwdg.de; Tel.: +49-551-395-414 \\ Received: 7 May 2018; Accepted: 30 May 2018; Published: 31 May 2018 \\ check for \\ updates
}

\begin{abstract}
Numerous lncRNAs exhibit circadian rhythms, sometimes with high amplitudes. Therefore, they are controlled by cellular circadian oscillators. However, they also seem to influence circadian clocks, as shown by the important core oscillator gene Per2, at which antiphasic rhythms of Per 2 mRNA and its antisense lncRNA are generated. Circadian cycles have also been described for enhancer and super-enhancer lncRNAs. Various lncRNAs are involved in the generation of the rhythm in the pineal gland, which secretes the circadian regulator molecule, melatonin. This compound acts pleiotropically in presumably all tissues and nucleate cells. At least, some of its effects are mediated by sirtuin 1 (SIRT1). SIRT1 enhances circadian amplitudes as an accessory oscillator component and participates in numerous regulation mechanisms. The interrelated actions of circadian oscillators, melatonin and SIRT1 apparently control at least $30 \%$ of all coding genes, processes that involve numerous IncRNAs.
\end{abstract}

Keywords: antisense RNA; circadian; lncRNA; melatonin; miRNA; sirtuin

\section{Introduction}

The importance of noncoding RNAs in the regulation of cellular processes has become one of the hottest topics of the last few years. Although countless publications have addressed the roles of microRNAs (miRNAs), the elucidation of functions of long noncoding RNAs (lncRNAs) is still an emerging field which receives rapidly increasing attention. In functional terms, lncRNAs are highly heterogeneous. Some of them control mRNA translation and turnover, either by direct interactions or by sponging miRNAs; others modulate protein degradation; participate in intracellular translocation; act as enhancer RNAs (eRNAs) with a presumed role in chromatin looping between enhancer and promoter; or are involved in signaling pathways [1]. Their origin is likewise divergent. Some of them are formed at or close to coding genes, others in intergenic regions. They may be transcribed from specific initiation points, either unidirectionally or bidirectionally, as known from the 2D type of eRNAs, or, in the case of antisense RNAs (asRNAs), in the reverse direction relative to hnRNA synthesis [2]. Differences have also been identified in histone $\mathrm{H} 3$ modification required for local nucleosome eviction. While lysine 4 is typically trimethylated (K4me3) at the transcription start of coding genes and several lncRNAs, too, monomethylation (K4me1) is typical for 2D eRNAs, whereas $\mathrm{H} 3$ acetylation (K56ac) is required for asRNAs and upstream-directed transcription of 2D eRNAs [2]. Presumably, the interest in these molecules will strongly rise because of the recent focus on super-enhancer lncRNAs (also known as super-lncRNAs) [3-5]. The numbers of different lncRNAs per cell is remarkable. In various tissues so far tested, between 2000 and over 4000 different lncRNAs are expressed [5]. Among them, over 20 to about 140 were classified as super-enhancer lncRNAs [5]. Importantly, these long RNAs are more highly transcribed and obviously more stable than shorter 
eRNAs ("normal" enhancer RNAs) [4]. Approximately 15\% of the super-enhancer lncRNAs have been identified as antisense transcripts of protein-coding genes, but antisense sequences are also known for various other lncRNAs. In functional terms, the known super-enhancer lncRNAs are mainly seen as safeguards for the correct progressing of cell developmental programs [3,4]. Therefore, such molecules will likely be controlled by differentiation factors. However, this does not exclude the existence of super-enhancer lncRNAs with nondevelopmental functions, especially if a higher number of genes have to be jointly controlled, as discussed below. Super-enhancer lncRNAs are assumed to act, among other functions, as scaffolds for enhancer-binding proteins. Interestingly, the anchoring regions of these IncRNAs at the DNA were found to be distant to the binding sites of master transcription factors [5]. This may be in accordance with the formation of lncRNA:DNA:DNA triplex structures that are based on the presence of a triplex-forming repeat domain that interacts with DNA anchor sites. Classic transcription factors cannot be expected to interact with triplexes. Insofar, the majority of other lncRNAs, which do not target super-enhancers and do not form triplex structures, have to be distinguished.

These other lncRNAs, which do not primarily sustain a developmental cell program, but are rather involved in more flexible responses according to rapidly changing demands of regulation, can be assumed to be controlled by different mechanisms. Of course, these more flexibly operating molecules may be also associated with enhancer regions and may target a certain number of enhancers. However, differentiating judgments are required since lncRNAs serve numerous divergent functions. They may act as transcriptional guides, activators or repressors; interact with specific chromatin structures; sequester mRNAs; act as miRNA sponges; be processed to form other miRNAs; and be involved in the regulation of mRNA and miRNA editing, of splicing and of translational efficiency [6-9]. This diversity of functions is obviously associated with another diversity of control factors that give rise to their formation, decay and abundance. To squeeze this remarkable multitude of functions and regulators into a general scheme appears to be highly unpromising. Therefore, it seems more worthwhile to identify, in a first run, connections between lncRNAs and more globally acting factors and cellular machineries that orchestrate a high number of physiological and cell biological functions.

\section{Orchestrating Regulators: Melatonin, Sirtuins and the Circadian Oscillator System}

These possibilities shall be outlined on the basis of a few examples of molecules and mechanisms that are relevant to the majority of cells. Despite the high number of hormones and other humoral factors that exist in a mammalian body, only a minority target many different cell types. However, a cellular system exists that is present in, perhaps, all nucleate cells and which is connected to pleiotropically-acting hormones and omnipresent cellular regulators to fulfill the criterion of orchestrating machinery that impacts a high number of functions. This is the circadian system. As a whole, it is much more than just the circadian master clock in the hypothalamic suprachiasmatic nucleus ( $\mathrm{SCN}$ ). In fact, it is composed of countless oscillators present in, at least, the majority of cells, which vary in their degree of dependence on the SCN $[10,11]$. Additionally, the circadian system controls a hormone that acts on almost all cells, melatonin [12]. It also influences many other hormones, among them the glucocorticoids, which exhibit rhythms of high amplitude and also target various different cell types [13-15]. Moreover, melatonin upregulates, in nontumor cells, sirtuin 1 (SIRT1) [11,16], which is not only an aging suppressor and a contributor to metabolic sensing, but, importantly, an accessory oscillator component that enhances circadian amplitudes in central and peripheral oscillators [16-18].

According to actual estimations, at least $30 \%$ of all mammalian genes are under circadian control [19] and are additionally subjected to posttranscriptional regulation [20]. Taken together, the circadian multioscillator system including its pleiotropic hormonal regulators, melatonin and glucocorticoids, has a remarkably broad impact that exceeds, in systemic terms, that of most other master regulators. Notably, the circadian system, melatonin and SIRT1 share the property of jointly declining in the course of aging [16], which is indicative of their tight connections. This seems to 
comprise mediation of melatonin effects via SIRT1. Another aspect being worth being kept in mind is the dysregulation of the circadian system in cancer cells, which have to epigenetically silence some circadian oscillator genes because of their tumor suppressor properties [11,21]. Therefore, a systematic look at the ensemble of circadian oscillators, melatonin and SIRT1 may be of relevance in a pathological context. Moreover, this will be particularly promising in elucidating properties and actions of master regulators and will reveal actions beyond the primary signaling pathways of a hormone. With some likelihood, this may also be assumed for the contributions of lncRNAs. Pertinent actual knowledge is encouraging and is summarized here.

\section{Cycling LncRNAs}

Many publications on lncRNAs and other noncoding RNAs have been related to pathologies. However, it seems important to direct an investigators' attention to the fact that many diseases are associated with deviations in the circadian system $[10,22,23]$. With regard to the necessity of suppressing circadian genes with antitumor activities, this is especially the case in tumor cells [11,21]. Therefore, circadian variations in lncRNAs should be of interest in the pathological context. Circadian rhythms in lncRNA expression have been repeatedly shown since 2012 and are of quantitative relevance. One of the first respective studies demonstrated day/night differences in 112 lncRNAs in the rat pineal gland [24], the organ that generates a rhythm of melatonin formation with an extremely high amplitude (minimum/maximum ratio often above 1:10). The amplitudes of the cycling lncRNAs varied substantially between these molecule species, but some of them attained amplitudes that were even larger than that of melatonin, e.g., in lncSN81 (1:36), lncSN012 (1:50), lncSN004 (1:178), and lncSN001 (1:267). It would be hard to believe that this strongly pronounced rhythmicity should not be of relevance for the rhythmic behavior of the gland and melatonin formation. In two cases, lncSN001 and lncSN016, the input from the SCN was decisive, since (i) their rhythms were abolished by surgically interrupting the neuronal pathway to the pineal and (ii) because their expression was enhanced by $\beta$-adrenergic stimulation, which corresponds to the final step of neuronal activation of pineal melatonin synthesis via postganglionic sympathetic fibers. Moreover, some of the pineal lncRNAs were shown to be downregulated by light at night [24]. Next, circadian rhythms of lncRNAs were described in murine liver [25] and retina [26], in either organ for 16 cycling lncRNAs from intergenic regions.

Another, very specific and, to some extent, unusual case was reported for the Prader-Willis locus SNORD116, whose transcript is spliced into several snoRNAs and the lncRNA 116HG. In murine brain regions, such as the cortex, forebrain, hindbrain, hypothalamus, hippocampus and cerebellum, 116HG was shown to form a subnuclear cloud that cycled in its size and was associated with large-scale chromatin decondensation [27]. Another relationship to the circadian system may be deduced from the finding that SNORD116-deleted mice were dysregulated in the expression of the circadian core oscillator genes Cry1, Per2, and Clock, perhaps because of the absence of 116HG [27].

A recent study on mouse livers revealed an astonishingly high number of cycling lncRNAs [28]. Among 8705 lncRNA clusters (a cluster comprising splice variants of the same transcript), 604 clusters were shown to be expressed in a circadian fashion. Notably, this number exceeded by far that of the protein-coding genes (2245) under circadian control. Additional information was presented for rat liver and nonhepatic murine tissues. Although the absolute expression levels of the circadian lncRNA genes was only in the range of $11 \%$ of protein-coding genes, the amplitudes of the lncRNA rhythms were typically much larger than those of the latter. Another important aspect that sheds light on the relationship between oscillators and circadian-controlled protein-coding genes concerns the fact that a high number of circadian lncRNAs, estimated to amount to 281, were expressed at enhancer regions. Notably, 50 of them were classified as being associated with super-enhancers. One case of a super-enhancer, Inc-Crot (=lnc_00179) was analyzed in detail and shown to be present in both the nucleus and the cytoplasm of neurons in the hippocampal CA3 region. Moreover, lnc-Crot was found to be more enriched in the nucleus than the transcript of the corresponding coding gene, 
Crot (carnitine O-octanoyltransferase). Another relationship between the enhancer-associated lncRNAs and circadian properties became evident by high frequencies of binding sites for two circadian oscillator components, BMAL1 and REV-ERB $\alpha$ [28], which bind to either the E-box or the RORE (ROR response element), respectively, in the promoters of two different types of core oscillator genes and circadian-controlled genes.

With high likelihood, the roles of circadian lncRNAs are not uniform. This is already evident from the fact that a certain fraction represent antisense RNAs. In the aforementioned study on murine liver [28], 23\% of the lncRNAs were antisense, whereas only $7 \%$ were sense-overlapping and the majority (53\%) intergenic. About $17 \%$ were bi-directional, as typically found in the category of $2 \mathrm{D}$ eRNAs [29]. A very specific case of interest concerns the antisense-lncRNA of the Per 2 gene, i.e., one of the most important core oscillator genes, a finding that implies an additional regulation mechanism within the clock. This antisense RNA (asPer2) was first discovered in mouse liver [25]. The asPer2 was shown to oscillate in antiphase to Per 2 mRNA (Figure 1), which was indicative of an inhibitory or suppressive role of the lncRNA. Two models have been recently proposed to explain this, either a pre-transcriptional mechanism, in which asPer 2 prevents Per 2 transcription by interacting with the gene, or a post-transcriptional mechanism, in which a sense-antisense RNA duplex prevents translation and is rapidly degraded [30]. To date, no decision between these possibilities has been possible. Generally, the silencing by an antisense RNA has also been observed in other cases beyond the circadian regulation [31]; however, the mechanisms remain to be studied. Nevertheless, the presence of an antisense-lncRNA may not be taken as a proof for silencing, since, in another case, that of the MACC1 (MET transcriptional regulator) gene, the antisense transcript was reported to indirectly upregulate MACC 1 by enhancing mRNA stability via AMPK/Lin28 signaling [32]. A further example for the enhancement of gene expression by an antisense RNA was reported for Sirt1 mRNA, in which the asSirt1 eliminated a targeting microRNA, miR-34a [33]; a finding with relevance to the circadian system.

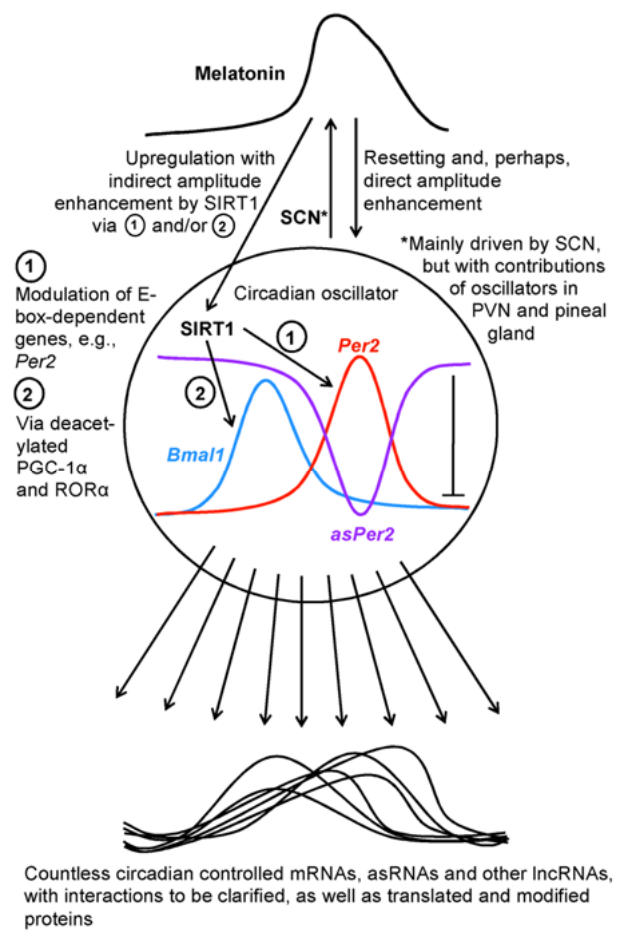

Figure 1. A schematic overview of the connections between circadian oscillators, melatonin, SIRT1 and downstream transcripts. Abbreviations: asPer2, antisense Per2 lncRNA; asRNAs, antisense RNAs; Bmal1, brain and muscle arylhydrocarbon receptor nuclear translocator-like protein mRNA; Per2, Period 2 gene; PGC- $1 \alpha$, poly ADP ribose polymerase- $\gamma$ coactivator- $1 \alpha$; PVN, paraventricular nucleus; $\mathrm{ROR} \alpha$, retinoic acid receptor-related orphan receptor- $\alpha ; \mathrm{SCN}$, suprachiasmatic nucleus; SIRT1, sirtuin 1. 


\section{Functional Diversity of Cycling LncRNAs and Their Regulators}

The importance of lncRNAs in the circadian system is certainly not restricted to the direct control of rhythmic gene expression by solely cellular oscillator mechanisms, because physiological regulators orchestrate the system on a humoral basis. Among them, two types of hormones are of particular relevance, melatonin and glucocorticoids, because both exhibit circadian rhythms of high amplitude. In either case, they were shown to influence the expression of lncRNAs. Concerning glucocorticoids, numerous publications have already addressed their relation to lncRNAs, however, mainly in the context of cancer and immunology, which would exceed the scope of this article, but not yet with reference to circadian rhythmicity. With regard to melatonin's anti-inflammatory actions that comprise downregulation of various proinflammatory cytokines, a glucocorticoid-related study on TNF $\alpha$ shall be briefly mentioned [34]. TNF $\alpha$ was shown to regulate 54 lncRNAs transcribed from pseudogenes. One of these, Lethe, was upregulated by both glucocorticoids and proinflammatory cytokines via NF- $\mathrm{KB}$ and exerted a negative feedback to this transcription factor by preventing DNA binding of the NF- $k B$ subunit RelA. Moreover, Lethe decreases in the course of aging [34], a finding of interest in correspondence to comparable declines in the circadian system, melatonin and SIRT1 levels [16]. This may be more than just a correlation, since NF- $\mathrm{KB}$ activation is known to be antagonized by melatonin [35-37] and also by its partial downstream factor SIRT1 [36,38,39].

The capability of melatonin in regulating the expression of lncRNAs should be regarded as an emerging field that requires future efforts. However, with regard to the pleiotropy of this orchestrating regulator, many more effects of this type have to be expected. The actual, still limited knowledge on melatonin effects via lncRNAs, has been recently summarized [40]. An lncRNA with functions different from those of the other molecules discussed here concerns the telomeric repeat RNA TERRA [41]. In other cases, melatonin was described to either down- or upregulate lncRNAs. In human aortic endothelial cells, melatonin was concluded to decrease the propyroptotic lncRNA MEG3, a molecule that is targeted by the antipyroptotic miR-223, which seems to mediate the melatonin effect [42]. In cardiac progenitor cells exposed to oxidative stress, melatonin prevented a decrease in the IncRNA H19 and its derivative miR-675. A protective effect was concluded to consist in the interaction of this microRNA with its target, ubiquitin-specific peptidase 10 (USP10) mRNA [43]. In hepatocellular carcinoma cells, melatonin was reported to increase, via FOXA2, the lncRNA CPS1 intronic transcript CPS1-IT1. This transcript reduced HIF-1 $\alpha$, an effect that was attributed to reductions in epithelial-mesenchymal transition, metastasis and tumor growth in vivo [44].

\section{Sirtuin 1 as a Downstream Factor of Melatonin and a Circadian Regulator}

While the direct effects of melatonin on IncRNAs do not yet provide a coherent picture, the emerging evidence for an, at least, partial mediation of melatonin's actions by SIRT1 [16,45-50] opens new avenues for understanding the influence of the pineal hormone in the regulation of noncoding RNAs and also offers another nexus to the circadian system. Concerning the relationship between SIRT1 and IncRNAs, several publications have addressed this in the context of cancer, e.g., in connection with the metastasis-associated IncRNA MALAT1 or with SIRT1-antisense RNA. These findings may be of high interest to tumor biology. They seem to specifically reflect the situation in dysregulated oscillators, but not physiological signaling in nontumor cells. Therefore, these results will not be discussed here in all their details. Apart from the cancer-specific deviations in PER2 and SIRT1 expression [11,21], a further hint for circadian dysregulation at the oscillator level in tumor cells can be deduced from the interaction of MALAT1 and DBC1 (depleted in breast cancer 1) [51], an accessory oscillator component that regulates REV-ERB $\alpha$ and, therefore, affects BMAL1 expression [52,53]. The interaction with MALAT1 was shown to result in enhanced SIRT1 activity [51]. However, the increase should not be misinterpreted, because this reflects in cancer cells a rather unfavorable dysregulation of the circadian oscillator, not a favorable amplitude enhancement [11,21].

In nontumor cells, the relationship between SIRT1 and lncRNAs has been addressed a couple of times, though, in entirely different systems. Effects of lncRNAs on SIRT1 expression were shown in the 
case of Sirt1-antisense RNA, which increases Sirt1 mRNA availability [33]. This was also observed in the context of myogenic differentiation [54] and in endothelial progenitor cells [55]. In hepatocellular hepatoma, SIRT1 expression was increased by the lncRNA HULC [56]. The lncRNA HOTAIR was shown to downregulate Sirt1 expression in the liver [57]. In alveolar epithelial cells, decreases of the IncRNA SAL-RNA1 were associated with reduced SIRT1 expression [58]. Among the effects of SIRT1 on $\operatorname{lncRNAs}$, a suppression of HIF1 $\alpha$-antisense RNA was reported [59].

\section{Conclusions}

In total, our knowledge on the relationship between lncRNAs and SIRT1 is still fragmentary, but certainly worth further exploration. Generally, downstream factors of SIRT1 have been mostly sought in the field of deacetylatable proteins and rarely among noncoding RNAs. While countless publications have described the targeting of Sirt1 mRNA by microRNAs, a microRNA as a mediator of SIRT1 signaling has only exceptionally been identified, e.g., in the case of miR-182 [60]. It would not be a surprise if many more downstream miRNAs and lncRNAs would exist too. In the future, investigators may not only seek for regulators of SIRT1 expression but also consider a reverse relationship. At least indirectly, SIRT1 should be assumed to modulate numerous lncRNAs and other noncoding RNAs by its effects on the circadian system, which generates numerous rhythms of lncRNAs [25-28]. As far as melatonin acts via SIRT1 or directly resets and modulates circadian rhythms (cf. Figure 1), additional actions on cycling lncRNAs should be expected. In any case, circadian oscillators represent orchestrating machineries that control a considerable fraction of genes whose expression has, almost inevitably, to be subject to modulation by the various types of lncRNAs.

Conflicts of Interest: The author declares no conflict of interest.

\section{References}

1. Noh, J.H.; Kim, K.M.; McClusky, W.G.; Abdelmohsen, K.; Gorospe, M. Cytoplasmic functions of long noncoding RNAs. Wiley Interdiscip. Rev. RNA 2018, 9, e1471. [CrossRef] [PubMed]

2. Ard, R.; Allshire, R.C.; Marquardt, S. Emerging properties and functional consequences of noncoding transcription. Genetics 2017, 207, 357-367. [PubMed]

3. Pefanis, E.; Wang, J.; Rothschild, G.; Lim, J.; Kazadi, D.; Sun, J.; Federation, A.; Chao, J.; Elliott, O.; Liu, Z.P.; et al. RNA exosome-regulated long non-coding RNA transcription controls super-enhancer activity. Cell 2015, 161, 774-789. [CrossRef] [PubMed]

4. Alvarez-Dominguez, J.R.; Knoll, M.; Gromatzky, A.A.; Lodish, H.F. The super-enhancer-derived alncRNA-EC7/Bloodlinc potentiates red blood cell development in trans. Cell Rep. 2017, 19, 2503-2514. [CrossRef] [PubMed]

5. Soibam, B. Super-lncRNAs: Identification of lncRNAs that target super-enhancers via RNA:DNA:DNA triplet formation. RNA 2017, 23, 1729-1742. [CrossRef] [PubMed]

6. Rashid, F.; Shah, A.; Shan, G. Long non-coding RNAs in the cytoplasm. Genom. Proteom. Bioinform. 2016, 14, 73-80. [CrossRef] [PubMed]

7. Ahadi, A.; Brennan, S.; Kennedy, P.J.; Hutvagner, G.; Tran, N. Long non-coding RNAs harboring miRNA seed regions are enriched in prostate cancer exosomes. Sci. Rep. 2016, 6, 24922. [CrossRef] [PubMed]

8. Salviano-Silva, A.; Lobo-Alves, S.C.; Almeida, R.C.; Malheiros, D.; Petzl-Erler, M.L. Besides pathology: Long non-coding RNA in cell and tissue homeostasis. Noncoding RNA 2018, 4, 3. [CrossRef] [PubMed]

9. Pereira Fernandes, D.; Bitar, M.; Jacobs, F.M.J.; Barry, G. Long non-coding RNAs in neuronal aging. Noncoding RNA 2018, 4, 12. [CrossRef] [PubMed]

10. Hardeland, R.; Madrid, J.A.; Tan, D.X.; Reiter, R.J. Melatonin, the circadian multioscillator system and health: The need for detailed analyses of peripheral melatonin signaling. J. Pineal Res. 2012, 52, 139-166. [CrossRef] [PubMed]

11. Hardeland, R. Melatonin and the pathologies of weakened or dysregulated circadian oscillators. J. Pineal Res. 2017, 62, e12377. [CrossRef] [PubMed] 
12. Hardeland, R.; Cardinali, D.P.; Srinivasan, V.; Spence, D.W.; Brown, G.M.; Pandi-Perumal, S.R. MelatoninA pleiotropic, orchestrating regulator molecule. Prog. Neurobiol. 2011, 93, 350-384. [CrossRef] [PubMed]

13. Chung, S.; Son, G.H.; Kim, K. Adrenal peripheral oscillator in generating the circadian glucocorticoid rhythm. Ann. N. Y. Acad. Sci. 2011, 1220, 71-81. [CrossRef] [PubMed]

14. Spencer, R.L.; Chun, L.E.; Hartsock, M.J.; Woodruff, E.R. Glucocorticoid hormones are both a major circadian signal and major stress signal: How this shared signal contributes to a dynamic relationship between the circadian and stress systems. Front. Neuroendocrinol. 2017. [CrossRef] [PubMed]

15. Moreira, A.C.; Antonini, S.R.R.; De Castro, M. Mechanisms in endocrinology: A sense of time of the glucocorticoid circadian clock: From the ontogeny to the diagnosis of Cushing's syndrome. Eur. J. Endocrinol. 2018. [CrossRef] [PubMed]

16. Hardeland, R. Brain inflammaging: Roles of melatonin, circadian clocks and sirtuins. J. Clin. Cell. Immunol. 2018, 9, 543. [CrossRef]

17. Sahar, S.; Sassone-Corsi, P. The epigenetic language of circadian clocks. Handb. Exp. Pharmacol. 2013, 217, $29-44$.

18. Chang, H.C.; Guarente, L. SIRT1 mediates central circadian control in the SCN by a mechanism that decays with aging. Cell 2013, 153, 1448-1460. [CrossRef] [PubMed]

19. Torres, M.; Becquet, D.; Franc, J.L.; François-Bellan, A.M. Circadian processes in the RNA life cycle. Wiley Interdiscip. Rev. RNA 2018, 9, e1467. [CrossRef] [PubMed]

20. Honma, S. The mammalian circadian system: A hierarchical multi-oscillator structure for generating circadian rhythm. J. Physiol. Sci. 2018, 68, 207-219. [CrossRef] [PubMed]

21. Hardeland, R. Melatonin, noncoding RNAs, messenger RNA stability and epigenetics—Evidence, hints, gaps and perspectives. Int. J. Mol. Sci. 2014, 15, 18221-18252. [CrossRef] [PubMed]

22. Brown, G.M.; McIntyre, R.S.; Rosenblat, J.; Hardeland, R. Depressive disorders: Processes leading to neurodegeneration and potential novel treatments. Prog. Neuropsychopharmacol. Biol. Psychiatry 2018, 80, 189-204. [CrossRef] [PubMed]

23. Hardeland, R. Circadian disruption, sleep loss, and low-grade inflammation. Res. Rev. Healthc. Open Access J. 2018, 1, 000109.

24. Coon, S.L.; Munson, P.J.; Cherukuri, P.F.; Sugden, D.; Rath, M.F.; Møller, M.; Clokie, S.J.H.; Fu, C.; Olanich, M.E.; Rangel, Z.; et al. Circadian changes in long noncoding RNAs in the pineal gland. Proc. Natl. Acad. Sci. USA 2012, 109, 13319-13324. [CrossRef] [PubMed]

25. Vollmers, C.; Schmitz, R.J.; Nathanson, J.; Yeo, G.; Ecker, J.R.; Panda, S. Circadian oscillations of protein-coding and regulatory RNAs in a highly dynamic mammalian liver epigenome. Cell Metab. 2012, 16, 833-845. [CrossRef] [PubMed]

26. Mustafi, D.; Kevany, B.M.; Genoud, C.; Bai, X.; Palczewski, K. Photoreceptor phagocytosis is mediated by phosphoinositide signaling. FASEB J. 2013, 27, 4585-4595. [CrossRef] [PubMed]

27. Powell, W.T.; Coulson, R.L.; Crary, F.K.; Wong, S.S.; Ach, R.A.; Tsang, P.; Yamada, N.A.; Yasui, D.H.; LaSalle, J.M. A Prader-Willis locus IncRNA cloud modulates diurnal genes and energy expenditure. Hum. Mol. Genet. 2013, 22, 4318-4328. [CrossRef] [PubMed]

28. Fan, Z.; Zhao, M.; Joshi, P.D.; Li, P.; Zhang, Y.; Guo, W.; Xu, Y.; Wang, H.; Zhao, Z.; Yan, J. A class of circadian long non-coding RNAs mark enhancers modulating long-range circadian gene regulation. Nucleic Acids Res. 2017, 45, 5720-5738. [CrossRef] [PubMed]

29. Chen, H.; Du, G.; Song, X.; Li, L. Non-coding transcripts from enhancers: New insights into enhancer activity and gene expression regulation. Genom. Proteom. Bioinform. 2017, 15, 201-207. [CrossRef] [PubMed]

30. Battogtokh, D.; Kojima, S.; Tyson, J.J. Modeling the interactions of sense and antisense Period transcripts in the mammalian circadian clock network. PLoS Comput. Biol. 2018, 14, e1005957. [CrossRef] [PubMed]

31. Yuan, J.; Liu, Z.; Song, R. Antisense lncRNA As-SLC7A11 suppresses epithelial ovarian cancer progression mainly by targeting SLC7A11. Pharmazie 2017, 72, 402-407. [PubMed]

32. Zhao, Y.; Liu, Y.; Lin, L.; Huang, Q.; He, W.; Zhang, S.; Dong, S.; Wen, Z.; Rao, J.; Liao, W.; et al. The lncRNA MACC1-AS1 promotes gastric cancer cell metabolic plasticity via AMPK/Lin28 mediated mRNA stability of MACC1. Mol. Cancer 2018, 17, 69. [CrossRef] [PubMed]

33. Wang, G.Q.; Wang, Y.; Xiong, Y.; Chen, X.C.; Ma, M.L.; Cai, R.; Gao, Y.; Sun, Y.M.; Yang, G.S.; Pang, W.J. Sirt1 AS lncRNA interacts with its mRNA to inhibit muscle formation by attenuating function of miR-34a. Sci. Rep. 2016, 6, 21865. [CrossRef] [PubMed] 
34. Rapicavoli, N.A.; Qu, K.; Zhang, J.; Mikhail, M.; Laberge, R.M.; Chang, H.Y. A mammalian pseudogene lncRNA at the interface of inflammation and anti-inflammatory therapeutics. Elife 2013, 2, e00762. [CrossRef] [PubMed]

35. Korkmaz, A.; Rosales-Corral, S.; Reiter, R.J. Gene regulation by melatonin linked to epigenetic phenomena. Gene 2012, 503, 1-11. [CrossRef] [PubMed]

36. Nopparat, C.; Sinjanakhom, P.; Govitrapong, P. Melatonin reverses $\mathrm{H}_{2} \mathrm{O}_{2}$-induced senescence in $\mathrm{SH}-\mathrm{SY} 5 \mathrm{Y}$ cells by enhancing autophagy via sirtuin 1 deacetylation of the RelA/p65 subunit of NF-kB. J. Pineal Res. 2017, 63, e12407. [CrossRef] [PubMed]

37. Guo, Y.; Sun, J.; Li, T.; Zhang, Q.; Bu, S.; Wang, Q.; Lai, D. Melatonin ameliorates restraint stress-induced oxidative stress and apoptosis in testicular cells via NF-kB/iNOS and Nrf2/HO-1 signaling pathway. Sci. Rep. 2017, 7, 9599. [CrossRef] [PubMed]

38. Li, X.; Jiang, Z.; Li, X.; Zhang, X. SIRT1 overexpression protects non-small cell lung cancer cells against osteopontin-induced epithelial-mesenchymal transition by suppressing NF-кB signaling. OncoTargets Ther. 2018, 11, 1157-1171. [CrossRef] [PubMed]

39. Fan, J.; Guang, H.; Zhang, H.; Chen, D.; Ding, L.; Fan, X.; Xue, F.; Gan, Z.; Wang, Y.; Mao, S.; et al. SIRT1 mediates apelin-13 in ameliorating chronic normobaric hypoxia-induced anxiety-like behavior by suppressing NF-kB pathway in mice hippocampus. Neuroscience 2018, 381, 22-34. [CrossRef] [PubMed]

40. Su, S.C.; Reiter, R.J.; Hsiao, H.Y.; Chung, W.H.; Yang, S.F. Functional interaction between melatonin signaling and noncoding RNAs. Trends Endocrinol. Metab. 2018. [CrossRef] [PubMed]

41. Yu, S.; Wang, X.; Geng, P.; Tang, X.; Xiang, L.; Lu, X.; Li, J.; Ruan, Z.; Chen, J.; Xie, G.; et al. Melatonin regulates PARP1 to control the senescence-associated secretory phenotype (SASP) in human fetal lung fibroblast cells. J. Pineal Res. 2017, 63, e12405. [CrossRef] [PubMed]

42. Zhang, Y.; Liu, X.; Bai, X.; Lin, Y.; Li, Z.; Fu, J.; Li, M.; Zhao, T.; Yang, H.; Xu, R.; et al. Melatonin prevents endothelial cell pyroptosis via regulation of long noncoding RNA MEG3/miR-223/NLRP3 axis. J. Pineal Res. 2018, 64, e12449. [CrossRef] [PubMed]

43. Cai, B.; Ma, W.; Bi, C.; Yang, F.; Zhang, L.; Han, Z.; Huang, Q.; Ding, F.; Li, Y.; Yan, G.; et al. Long noncoding RNA H19 mediates melatonin inhibition of premature senescence of c-kit+ cardiac progenitor cells by promoting miR-675. J. Pineal Res. 2016, 61, 82-95. [CrossRef] [PubMed]

44. Wang, T.H.; Wu, C.H.; Yeh, C.T.; Su, S.C.; Hsia, S.M.; Liang, K.H.; Chen, C.C.; Hsueh, C.; Chen, C.Y. Melatonin suppresses hepatocellular carcinoma progression via lncRNA-CPS1-IT-mediated HIF-1 $\alpha$ inactivation. Oncotarget 2017, 8, 82280-82293. [PubMed]

45. Zhao, L.; An, R.; Yang, Y.; Yang, X.; Liu, H.; Yue, L.; Li, X.; Lin, Y.; Reiter, R.J.; Qu, Y. Melatonin alleviates brain injury in mice subjected to cecal ligation and puncture via attenuating inflammation, apoptosis, and oxidative stress: The role of SIRT1 signaling. J. Pineal Res. 2015, 59, 230-239. [CrossRef] [PubMed]

46. Yang, Y.; Jiang, S.; Dong, Y.; Fan, C.; Zhao, L.; Yang, X.; Li, J.; Di, S.; Yue, L.; Liang, G.; et al. Melatonin prevents cell death and mitochondrial dysfunction via a SIRT1-dependent mechanism during ischemic-stroke in mice. J. Pineal Res. 2015, 58, 61-70. [CrossRef] [PubMed]

47. Carloni, S.; Favrais, G.; Saliba, E.; Albertini, M.C.; Chalon, S.; Longini, M.; Gressens, P.; Buonocore, G.; Balduini, W. Melatonin modulates neonatal brain inflammation through ER stress, autophagy and miR-34a/SIRT1 pathway. J. Pineal Res. 2016, 61, 370-380. [CrossRef] [PubMed]

48. Zhao, L.; Liu, H.; Yue, L.; Zhang, J.; Li, X.; Wang, B.; Lin, Y.; Qu, Y. Melatonin attenuates early brain injury via the melatonin receptor/Sirt1/NF- $\mathrm{kB}$ signaling pathway following subarachnoid hemorrhage in mice. Mol. Neurobiol. 2017, 54, 1612-1621. [CrossRef] [PubMed]

49. Jenwitheesuk, A.; Boontem, P.; Wongchitrat, P.; Tocharus, J.; Mukda, S.; Govitrapong, P. Melatonin regulates the aging mouse hippocampal homeostasis via the sirtuin1-FOXO1 pathway. EXCLI J. 2017, 16, 340-353. [PubMed]

50. Yang, W.; Kang, X.; Qin, N.; Li, F.; Jin, X.; Ma, Z.; Qian, Z.; Wu, S. Melatonin protects chondrocytes from impairment induced by glucocorticoids via NAD ${ }^{+}$-dependent SIRT1. Steroids 2017, 126, 24-29. [CrossRef] [PubMed]

51. Chen, R.; Liu, Y.; Zhuang, H.; Yang, B.; Hei, K.; Xiao, M.; Hou, C.; Gao, H.; Zhang, X.; Jia, C.; et al. Quantitative proteomics reveals that long non-coding RNA MALAT1 interacts with DBC1 to regulate p53 acetylation. Nucleic Acids Res. 2017, 45, 9947-9959. [CrossRef] [PubMed] 
52. Chini, C.C.; Escande, C.; Nin, V.; Chini, E.N. DBC1 (Deleted in Breast Cancer 1) modulates the stability and function of the nuclear receptor Rev-erb $\alpha$. Biochem. J. 2013, 451, 453-461. [CrossRef] [PubMed]

53. Giguère, S.S.; Guise, A.J.; Jean Beltran, P.M.; Joshi, P.M.; Greco, T.M.; Quach, O.L.; Kong, J.; Cristea, I.M. The proteomic profile of Deleted in Breast Cancer 1 (DBC1) interactions points to a multifaceted regulation of gene expression. Mol. Cell. Proteom. 2016, 15, 791-809. [CrossRef] [PubMed]

54. Wang, Y.; Pang, W.J.; Wei, N.; Xiong, Y.; Wu, W.J.; Zhao, C.Z.; Shen, Q,W.; Yang, G.S. Identification, stability and expression of Sirt1 antisense long non-coding RNA. Gene 2014, 539, 117-124. [CrossRef] [PubMed]

55. Ming, G.F.; Wu, K.; Hu, K.; Chen, Y.; Xiao, J. NAMPT regulates senescence, proliferation, and migration of endothelial progenitor cells through the SIRT1 AS lncRNA/miR-22/SIRT1 pathway. Biochem. Biophys. Res. Commun. 2016, 478, 1382-1388. [CrossRef] [PubMed]

56. Xiong, H.; Ni, Z.; He, J.; Jiang, S.; Li, X.; He, J.; Gong, W.; Zheng, L.; Chen, S.; Li, B.; et al. LncRNA HULC triggers autophagy via stabilizing Sirt1 and attenuates the chemosensitivity of HCC cells. Oncogene 2017, 36, 3528-3540. [CrossRef] [PubMed]

57. Li, Z.Q.; Gu, X.Y.; Hu, J.X.; Ping, Y.; Li, H.; Yan, J.Y.; Li, J.; Sun, R.; Yu, Z.J.; Zhang, Y. Hepatitis C virus core protein impairs metabolic disorder of liver cell via HOTAIR-Sirt1 signalling. Biosci. Rep. 2016, 36, e00336. [CrossRef] [PubMed]

58. Gu, C.; Li, Y.; Liu, J.; Ying, X.; Liu, Y.; Yan, J.; Chen, C.; Zhou, H.; Cao, L.; Ma, Y. LncRNA-mediated SIRT1/FoxO3a and SIRT1/p53 signaling pathways regulate type II alveolar epithelial cell senescence in patients with chronic obstructive pulmonary disease. Mol. Med. Rep. 2017, 15, 3129-3134. [CrossRef] [PubMed]

59. Xu, Y.; Wang, S.; Tang, C.; Chen, W. Upregulation of long non-coding RNA HIF $1 \alpha$-anti-sense 1 induced by transforming growth factor- $\beta$-mediated targeting of sirtuin 1 promotes osteoblastic differentiation of human bone marrow stromal cells. Mol. Med. Rep. 2015, 12, 7233-7238. [CrossRef] [PubMed]

60. Wang, Y.; Zhao, X.; Wu, X.; Dai, Y.; Chen, P.; Xie, L. MicroRNA-182 mediates Sirt1-induced diabetic corneal nerve regeneration. Diabetes 2016, 65, 2020-2031. [CrossRef] [PubMed]

(C) 2018 by the author. Licensee MDPI, Basel, Switzerland. This article is an open access article distributed under the terms and conditions of the Creative Commons Attribution (CC BY) license (http:/ / creativecommons.org/licenses/by/4.0/). 